\title{
ECONOMIC LOAD DISPATCH OF NIGERIA INTEGRATED HIGH VOLTAGE GENERATION AND TRANSMISSION GRID USING BAT ALGORITHM
}

\author{
V. K. Abanihi ${ }^{1, *}$ and K. O. Ovabor ${ }^{2}$

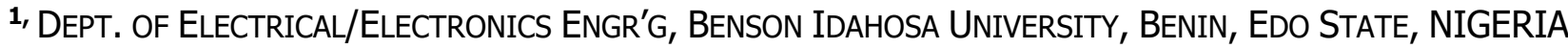 \\ 2, Ict Division, NATiOnal Agency fOR FoOd and DRUgs Admin. ANd CONTROL, (NAFDAC), Plot 1, \\ INDUSTRIAL ESTATE, LAGOS- OSHODI APAPA EXPRESS WAY, ISOLO, LAGOS STATE, NIGERIA \\ E-mail addresses: ${ }^{1}$ vabanihi@biu.edu.ng, ${ }^{2}$ ovabor.k@nafdac.gov.ng
}

\begin{abstract}
A BAT algorithm to solve economic load dispatch problem of the Nigerian integrated power system is presented in this paper. Data from Transmission Company of Nigeria (TCN) national control centre, Osogbo was collected from January 2010 to December 2015 and was used to develop cost function for the twenty-one (21) thermal stations contributing power to the national grid. The cost functions were optimized in MATLAB@ R2012a environment using Genetic Algorithm (GA), Particle Swarm Optimization (PSO), Simulated Annealing (SA) and Bat Algorithm (BA). The result obtained shows that using the optimization tools GA, PSO, SA and BA the cost of fuel for generation are $N 13,239,100.0, N 13,193,163.2, N 13,139,672.0$ and $N 13,105,495.2$ respectively, which shows that $B A$ gave the best result of minimizing fuel cost.
\end{abstract}

Keywords: economic, load dispatch, bat algorithm, simulated annealing, optimization

\section{INTRODUCTION}

In recent times around the world, power system has grown in complexity as regarding interconnection and increased power demand. Operators have shifted their focus towards better performance, increased customer centred operation, reduced cost, reliable and clean power [1]. The sole aim of Economic Load dispatch (ELD) is the operation of generation to produce energy at the lowest cost while satisfying system constraints by fulfilling the demand within several limits. This is not an easy task since there are a lot of factors need to be considered especially in the large interconnected power system. The primary objective of ELD is to schedule the committed generating units output so as to meet the required load demand at minimum cost satisfying all unit and system operational constraints [2].
The following conventional methods as reported by many authors have been used to solve the ELD problems: Bundle method, nonlinear programming, mixed integer linear programming, dynamic programming, quadratic programming, LaGrange relaxation method, network flow method, direct search method [3].

In practice ELD problems are nonlinear, non-convex problems that approaches local minimum severally due to the inclusion of valve point loading effect, multiple fuel options with many equality and inequality constraints. Conventional methods have failed to solve such problems as they are sensitive to initial estimates and converge into local optimal solution and computational complexity [4].

Literature is now full of many Biology-inspired metaheuristic algorithms because many researchers see it as an efficient way to deal with many hard

* Corresponding author, tel: $+234-803-410-2488$ 
combinatorial optimization problems and non-linear optimization constrained problems in general [5]. These algorithms are based on a particular successful mechanism of a biological phenomenon of Mother Nature in order to achieve optimization, such as the family of honey-bee algorithms, where the finding of an optimal solution is based on the foraging and storing the maximum amount of flowers' nectar [3]. A new algorithm that belongs in this category of the socalled nature inspired algorithms is the bat algorithm which is based on the echolocation behaviour of bats $[3,6]$.

The Nigerian national grid as at the year 2015 includes the twenty-one (21) thermal power station contributing power to the Nigeria Integrated power system, which includes eight privatised companiesthermal stations (Egbin ST, Sapele ST, Delta II-III, Delta IV, Geregu, Omotosho, Olorunsogo and Afam IV-V), Six NIPP-Stations (Sapele GT, Alaoji, Geregu, Olorunsogo, Omotosho and Ihovbor) and Seven IPPStations (Okpai, Afam VI, AES, Omoku, Ibom, Trans Amadi and Rivers). The grid is a rapidly growing power systems faced with complex operational challenges at different operating regimes. Indeed, it suffers from inadequate reactive power compensation leading to wide spread voltage fluctuations coupled with high technical losses and component over overloads during heavy system loading mode [7]. In Nigeria, the needs of electricity unity customers have been the reliability of electricity supply at an acceptable cost. The scheduling problem in electric power authority is as a result of the following constraints; fragile and inflexible state of the transmission network to wheel increased power levels, absence of state of the art dispatch facilities and high technical losses. Since power generation is dynamic, there is the need of sending the results of the ELD to all the power stations so as to meet up with the changes in the demand [2].

In this research paper therefore we present how the BAT algorithm can be used to solve the economic load dispatch of the Nigeria integrated power grid optimization problem. The effectiveness of proposed algorithm is demonstrated using the twenty-one thermal stations contributing power to the national grid as at the year 2015 .

\section{MATHEMATICAL FORMULATION OF THE ECONOMIC LOAD DISPATCH PROBLEM}

\subsection{Economic Dispatch}

The main objective of economic load dispatch of electric power generation is to schedule the online generating unit outputs so as to meet the load demand at minimum operating cost while satisfying all units and operational constraints of the power system. The economic dispatch problem is a constrained optimization problem and the mathematical optimization problem is as follows:

$$
\min F_{T}=\sum_{n=1}^{n} F_{n}\left(P_{n}\right)
$$

Where $F_{T}$ : total generation cost (Naira/hr) n: number of generators $P_{n}$ : real power generation of nth generator (MW) $F_{n}\left(P_{n}\right)$ : generation cost for $P_{n}$ Subject to a number of power systems network equality and inequality constraints [8]. These constraints include:

\subsubsection{System Active Power Balance}

To satisfy the power balance equation, the total power generated should be the same as total load demand plus the total line

$$
P_{D}+P_{L}-\sum_{n-1}^{n} P_{n}=0
$$

Where $P_{D}$ : total system demand (MW) $P_{L}$ : transmission loss of the system (MW) [9].

\subsubsection{Generation limits}

Generation output of each generator should be laid between maximum and minimum limits. The corresponding inequality constraints for each generator are

$$
P_{n, \text { min }} \leq P_{n} \leq P_{n, \max }
$$

Where $P_{n, \text { min: }}$ minimum power output limit of nth generator (MW) $P_{n, \max }$ : maximum power output limit of nth generator (MW). The generator cost function $F_{n}$ $\left(P_{n}\right)$ is usually expressed as a quadratic polynomial:

$$
F_{n}\left(P_{n}\right)=a_{n} P_{n}^{2}+b_{n} P_{n}+c_{n}
$$

Where $a_{n}, b_{n}$ and $c_{n}$ are fuel cost coefficients $[10,11]$.

\subsubsection{Network Losses}

Usually all the power generating stations are not located in the same place they are spread out geographically, the transmission network losses must be taken into account to achieve true economic dispatch. Network loss is a function of unit generation. To calculate network losses, two methods are in general used.

One is the penalty factors method and the other is the $B$ coefficients method, network losses are expressed as a quadratic function [12]:

$$
P_{L}=\sum_{m} \sum_{n} P_{m} B_{m n} P_{n}
$$


Where $B_{m n}$ constants are called B coefficients or loss coefficients [12-14].

\subsection{Bat Algorithm}

Bats are extremely interesting and attractive animals. They are the only animals that give birth to live babies with wings and they also have advanced capability of echolocation (the use of reflected sound waves for finding things) $[3,15]$. Most of bats use echolocation to a certain degree; among all the species, microbats are famous example as microbats use echolocation extensively, while megabats do not. Microbats use a type of sonar, called echolocation, to detect pry, avoid obstacles, and locate their roosting crevices in the dark $[3,16]$. If we idealize some of the echolocation characteristics of microbats, virous bat-inpired algorithms or bat algorithms can be developed. For simplicity, in our approach, the following approximate or idealized rules were used:

1. All bats echolocation to sense distance, and they also know the difference between food/prey and background barriers.

2. Bats fly randomly with velocity vi at position xi with a fixed frequency $f_{\min }$ (or wavelength $\lambda$ ), varying wavelength $\lambda$ (of frequency) of their emitted pulses and adjust the rate of pulse emission $r$ $\subset[0,1]$, depending on the proximity of their targets;

3. Although the loudness can vary in many ways, we assume that the loudness varies from a large (positive) $A_{0}$ to a minimum value Amin.

Another obvious simplification is that no ray tracing is used in estimating the time delay and three dimensional topographies. In addition to these simplified assumptions, the following approximations have been used, for simplicity. In general the frequency $f$ in a range of $[20 \mathrm{kHz}, 500 \mathrm{kHz}]$ corresponds to a range of wavelengths

$\left[\lambda_{\min }, \lambda_{\max }\right]$. For example, a frequency range of $[20 \mathrm{kHz}, 500 \mathrm{kHz}]$ corresponds to a range of wavelengths from $0.7 \mathrm{~mm}$ to $1.7 \mathrm{~mm}$ [15].

In simulations, we use virtual bats naturally. We have to define the rules how their positions $x i$ and velocities vi in a d-dimensional search space are updated. The new solutions $x_{i}^{0}$ and velocities $v_{i}^{0}$ at time step t are given by:

$$
\begin{gathered}
f_{i}=f_{\text {min }}+\left(f_{\text {max }}-f_{\text {min }}\right) \beta \\
v_{t}^{t}=v_{i}^{t-1}+\left(x_{i}^{t}-x_{0}\right) f_{i}
\end{gathered}
$$

Where $\beta \subset[0,1]$ is a random vector drawn from a uniform distribution. Here $\mathrm{x}_{0}$ is the current global best location (solution) which is located after comparing all the solutions among all the $\mathrm{n}$ bats. As the product $\lambda_{i} f_{i}$ is the other velocity increment, we can use either fi (or $\lambda_{i}$ ) to adjust the velocity change while fixing the other factor $\lambda_{i}\left(o r, f_{i}\right)$, depending on the type of the problem of interest [17]. For the local search part, once a solution is selected among the current best solutions, a new solution for each bat is generated locally using random walk:

$$
X_{\text {new }}=X_{\text {old }}+E \cdot A^{t}
$$

Where $E \subset[0,1]$ is a random number, while = $A^{t}=\pi A_{j}^{t} \phi$ is the average loudness of all the bats at this time step [18].

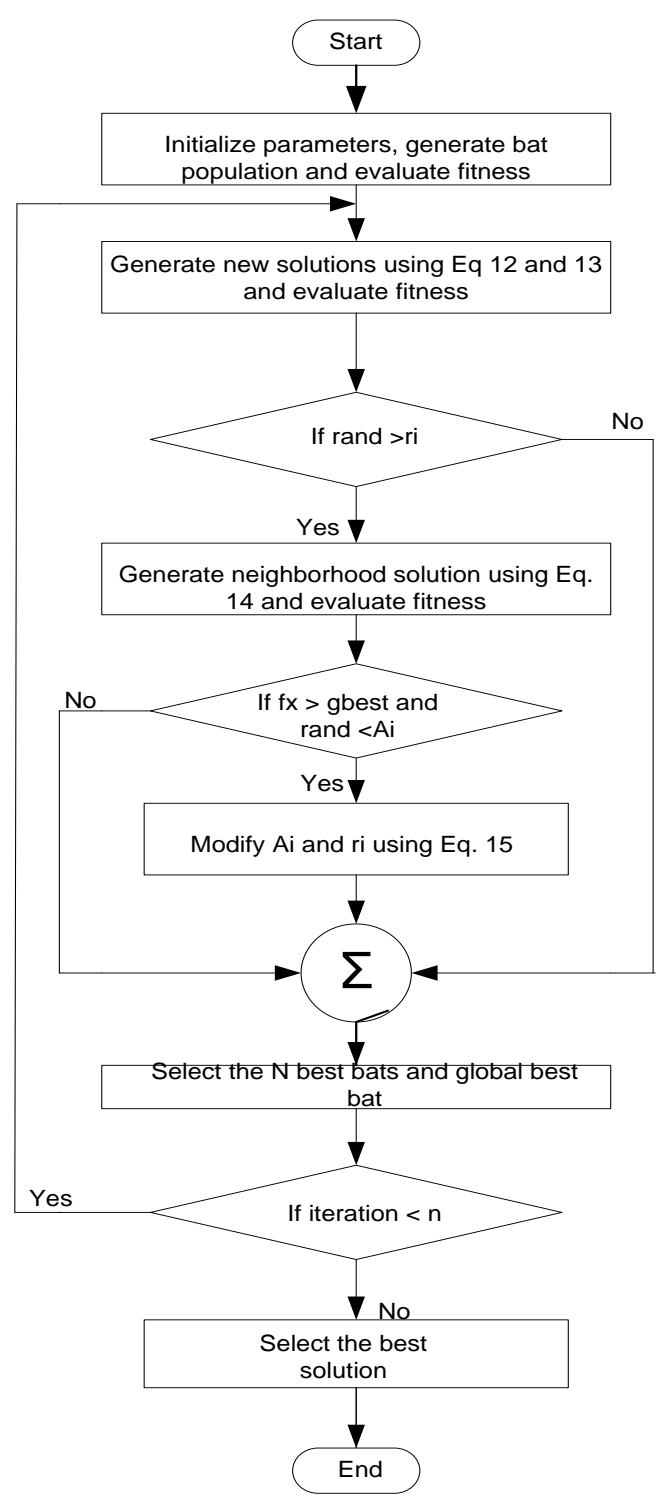

Figure 1: Flow Chart of Bat Algorithm

Vol. 38, No. 2, July 2019 
Based on the above approximations and idealization, the pseudo-code of the Bat Algorithm (BA) can be summarized below. The loudness usually decreases once a bat found its prey and rate of pulse emission increases. In our experiments, the loudness and pulse emission rate are varied once a solution is improved. The bat is moving towards optimal solution according to:

$$
A^{t+1}=\alpha A^{t}, r^{t+1}=r^{0}\left[1-e^{\gamma}\right]
$$

where $\alpha$ and $\gamma$ are constants [19]. Figure 1 represents flowchart of the Bat Algorithm.

\section{RESULTS AND DISCUSSION}

This paper presents the development of Bat Algorithm for solving an economic dispatch problem with the standardized 2015 model of the Nigerian network which comprises of 24 integrated power stations, out of which 3 are hydro whilst the remaining stations are thermal. The programs are written in MATLAB software package.

The generator cost coefficients; generation limits which is the quadratic cost functions for the various thermal units have been developed using least square curve fit to their actual operating cost data over a period of seven years. Table 1 presents the cost coefficients so obtained for the twenty-one thermal units and their minimum and maximum loading limits. The loss coefficients is obtained via loss parameter estimation based on several power flow scenarios [20] and B-coefficient matrix of the power stations are given in (10). Economic Load Dispatch solution for the twenty-one thermal stations is solved using BAT algorithm.

The cost coefficients and power limits of 21 thermal power stations are given Table 1 . The present work has been implemented in MATLAB 7.12.0.499 (R2012a) environment on a laptop computer (Window 8 pro, 64-bits operating system with processor speed of $2.8 \mathrm{GHz}$ and $4.0 \mathrm{~GB}$ RAM) for the solution of economic load dispatch problem of the Nigerian power system. The programs have been written (in $\mathrm{m}$ file) to calculate the solution of economic load dispatch problems and its results are presented. The techniques have been successfully applied to dispatch problems by considering all equality and inequality constraints.

Table 2 shows the power generated with the method of bat algorithm by varying demand.

Table 1: Cost coefficients and power limits of Nigerian 21 thermal power stations.

\begin{tabular}{|c|c|c|c|c|c|c|}
\hline $\mathrm{S} / \mathrm{N}$ & Power Stations & $a_{i}$ & $b_{i}$ & $\mathrm{C}_{\mathrm{i}}$ & Pimin (MW) & Pimax (MW) \\
\hline 1 & EGBIN ST(GAS) & 0.0000109 & 0.0284 & 3.92 & 118 & 1100 \\
\hline 2 & SAPELE ST & 0.0000591 & 0.0226 & 8.10 & 33 & 223 \\
\hline 3 & DELTA II-III & 0.0000757 & 0.0326 & 6.47 & 10 & 110 \\
\hline 4 & DELTA IV & 0.0000743 & 0.0334 & 9.85 & 22 & 434 \\
\hline 5 & GEREGU & 0.0000201 & 0.0313 & 1.25 & 14 & 450 \\
\hline 6 & OMOTOSHO & 0.0000514 & 0.0312 & 4.70 & 29 & 480 \\
\hline 7 & OLORUNSOGO & 0.0000294 & 0.0313 & 2.80 & 10 & 293 \\
\hline 8 & AFAM IV-V & 0.0000834 & 0.0289 & 2.03 & 24 & 453 \\
\hline 9 & SAPELE GT NIPP & 0.0000105 & 0.0227 & 5.60 & 30 & 373 \\
\hline 10 & ALAOJI NIPP & 0.0000200 & 0.0332 & 3.00 & 34 & 87 \\
\hline 11 & GEREGU NIPP & 0.0000223 & 0.0314 & 1.00 & 94 & 272 \\
\hline 12 & OLORUNSOGO NIPP & 0.0000287 & 0.0313 & 1.70 & 31 & 422 \\
\hline 13 & OMOTOSHO NIPP & 0.0000179 & 0.0313 & 2.64 & 20 & 225 \\
\hline 14 & IHOVBE NIPP & 0.0000200 & 0.0294 & 1.00 & 91 & 120 \\
\hline 15 & OKPAI & 0.0000326 & 0.0286 & 4.53 & 100 & 475 \\
\hline 16 & AFAM VI & 0.0000115 & 0.0286 & 8.00 & 45 & 656 \\
\hline 17 & AES & 0.0000133 & 0.0286 & 4.30 & 51 & 242 \\
\hline 18 & OMOKU & 0.0000442 & 0.0314 & 1.30 & 3 & 65 \\
\hline 19 & IBOM & 0.0000189 & 0.0312 & 4.60 & 10 & 101 \\
\hline 20 & TRANS AMADI & 0.0000315 & 0.0311 & 1.00 & 4 & 31 \\
\hline 21 & RIVERS IPP & 0.0000215 & 0.0318 & 6.00 & 20 & 160 \\
\hline
\end{tabular}


Economic Load Dispatch of Nigeria Integrated High Voltage Generation and Transmission Grid ... , V. K. Abanihi, et. al

Table 2: Results of Bat algorithm for the Nigerian 21 thermal power stations: Power dispatch (MW)

\begin{tabular}{clcccc}
\hline \multirow{2}{*}{ S/N } & \multirow{2}{*}{ Power Stations } & \multicolumn{4}{c}{ Load on Power Stations } \\
\cline { 3 - 6 } & & $2500 \mathrm{MW}$ & $3000 \mathrm{MW}$ & $3500 \mathrm{MW}$ & $4000 \mathrm{MW}$ \\
\hline 1. & EGBIN ST (GAS) & 496.5275 & 122.8602 & 605.3239 & 288.83 \\
2. & SAPELE ST & 34.9763 & 133.5573 & 185.8841 & 196.448 \\
3. & DELTA II-III & 10.001 & 19.9982 & 98.9096 & 88.8314 \\
4. & DELTA IV & 22.0039 & 61.0326 & 84.1693 & 107.2724 \\
5. & GEREGU & 191.2735 & 189.9218 & 360.2352 & 442.2986 \\
6. & OMOTOSHO & 320.8359 & 68.6196 & 181.1366 & 179.6815 \\
7. & OLORUNSOGO & 10.0625 & 29.9109 & 232.2028 & 278.7401 \\
8. & AFAM IV-V & 24 & 324.9404 & 156.3046 & 296.502 \\
9. & SAPELE GT NIPP & 101.8654 & 190.6673 & 140.6664 & 116.6221 \\
10. & ALAOJI NIPP & 34.0039 & 47.5819 & 44.4524 & 48.1721 \\
11 & GEREGU NIPP & 94.0002 & 221.9574 & 136.9487 & 198.4023 \\
12 & OLORUNSOGO NIPP & 31.0156 & 233.4077 & 418.4326 & 365.4274 \\
13 & OMOTOSHO NIPP & 183.6467 & 119.7283 & 194.2104 & 141.7964 \\
14 & IHOVBE NIPP & 92.1441 & 103.9853 & 93.2798 & 112.531 \\
15 & OKPAI & 128.1011 & 272.8071 & 113.4729 & 233.0529 \\
16 & AFAM VI & 480.9069 & 497.5713 & 74.8461 & 585.8328 \\
17 & AES & 193.03 & 192.9541 & 171.6475 & 119.293 \\
18 & OMOKU & 3 & 49.1825 & 8.7339 & 23.1311 \\
19 & IBOM & 24.605 & 58.368 & 53.3774 & 63.081 \\
20 & TRANS AMADI & 4 & 9.1717 & 8.6454 & 28.773 \\
21 & RIVERS IPP & 20.0003 & 51.7764 & 137.1203 & 85.2807 \\
\hline TOTAL COST(Naira/hr) & 170.8845 & 192.1326 & 210.8092 & 234.0267 \\
\hline PLoss(MW) & 11.74 & 12.33 & 13.67 & 15.73 \\
\hline CPUTime(Sec.) & 18.92 & 20.56 & 19.53 & 21.34 \\
\hline ITERATION & 90 & 100 & 90 & 100 \\
\hline
\end{tabular}

Table 3: Comparison results between $B A, G A, P S O$ and $S A$

\begin{tabular}{ccccc} 
& \multicolumn{5}{c}{ COST IN NAIRA } \\
\cline { 2 - 5 } METHODS & GA & PSO & SA & BA \\
LOADS & & & $9,628,892.0$ & $9,569,532.0$ \\
2500MW & $9,664,048,8$ & $9,638,876.8$ & $10,779,596.8$ & $10,759,425.6$ \\
3000MW & $10,877,059.2$ & $10,858,428.0$ & $11,869,642.4$ & $11,805,315.2$ \\
3000MW & $11,909,447.2$ & $11,880,534.4$ & 13.2 & $13,105,495.2$ \\
\hline
\end{tabular}

In Table 2 it is seen that the results obtained by the method of Bat algorithm are satisfactory.

To verify the effectiveness of our method (BA), we vary power demand from $2500 \mathrm{MW}$ to $4000 \mathrm{MW}$ and the results obtained by bat algorithm are compared with other methods such as Genetic Algorithm (GA), Particle Swarm Optimization PSO and Simulated Annealing (SA), and the results of this comparison are shown in Table 3.

From the technical report of the Transmission Company of Nigeria a flat rate of Two hundred and eighty Naira (N280) was the cost of one millimeter standard cubic feet (mmscf) of gas as supplied by the Gas Company of Nigeria (GCN) for the years 2014 and 2015. One hundred and Ninety five Naira (N195) was the cost of one millimeter Standared Cubic feet (mmscf) of Gas as supplied by the Gas Company of Nigeria in 2013 and 2012. This goes for One hundred and thirty five Naira (N135) and Thirty Naira (N30) for the years 2011 and 2010 respectively. A flat rate of N200 for one US Dollar has been used for 2014 and 2015 [21]. N198 for One US Dollar has been use to calculate the actual cost of Gas for runing the Power Stations and the results are shown in Table 3 
and Figure 2 have been used to illustrate this and it all show that BAT algorithm is the best optimization tool for the Nigerian Intergrated High Voltage Power System in terms of fuel cost as compared to GA, PSO and SA.

The results of comparison of table 3 are represented by the graph of the figure 2 .

The result of comparison shows that BA gives a cost of $\mathrm{N} 13,105,495.2$, GA gives a cost of $\mathrm{N} 13,239,100.0$, PSO gives $\mathrm{N} 13,193,163.2$ and $\mathrm{SA}$ gives N13,139,672.0 for 4000 MW power demand, which shows that the method of BAT algorithm gives better results as it minimizes the cost of fuel more than the other methods.

Additionally, the advantages of BAT algorithm are that BAT algorithm is easier to implement and there are fewer parameters to adjust.

\section{CONCLUSIONS}

The results obtained from applying the proposed BAT algorithm were compared to those obtained from $G A$, PSO and SA. The BAT algorithm has superior features, including quality of solution, stable iteration characteristics, and good computational efficiency. The comparison shows that BAT algorithm performs better than the other techniques.

Therefore, we are recommending BAT algorithm for the optimization of the Nigerian Power System as it is a promising technique for solving complicated problems in power system.

\section{REFERENCES}

[1] Buraimoh, E., Ejidokun, T. O. and Ayamolowo, O. J. "Optimization of an Expanded Nigeria Electricity Grid System using Economic Load Dispatch", ABUAD Journal of Engineering Research and Development, Vol. 1 No. 1, pp.61-66, Oct. 2018.

[2] Haruna, Y. S., Idris, S., Bakare G. A. and Abu, A. U. "Comparative Analysis of the Economic Load Dispatch Problem of the Nigerian Thermal Power Stations", Global Scientific Journals, vol. 6 No. 4, pp. 243-251, April 2018.

[3] Gherbi, Y. A., Bouzeboudja H. and Lakdja, F. "Economic Dispatch Problem using Bat Algorithm", Leonardo Journal of Sciences, Vol. 1 No. 24, pp. 75-84, June 2014.

[4] Mahor, A., Prasad, V. and Rangnekar, S. "Economic Dispatch using Particle Swarm Optimization: a Review", Renewable and Sustainable Energy Reviews, Vol. 1 No. 13 pp. 2134-2141 2009.

[5] Sudhakara, K. and Damodar, M. "Economic Load Dispatch Using Firefly Algorithm", International Journal of Engineering Research and Applications, Vol. 1 No. 2, pp.2325-2330, 2012.

[6] Yang, X. S., Nature-Inspired Metaheuristic Algorithms, United Kingdom, $2^{\text {nd }}$ ed. Frome: Luniver Press, 2010.

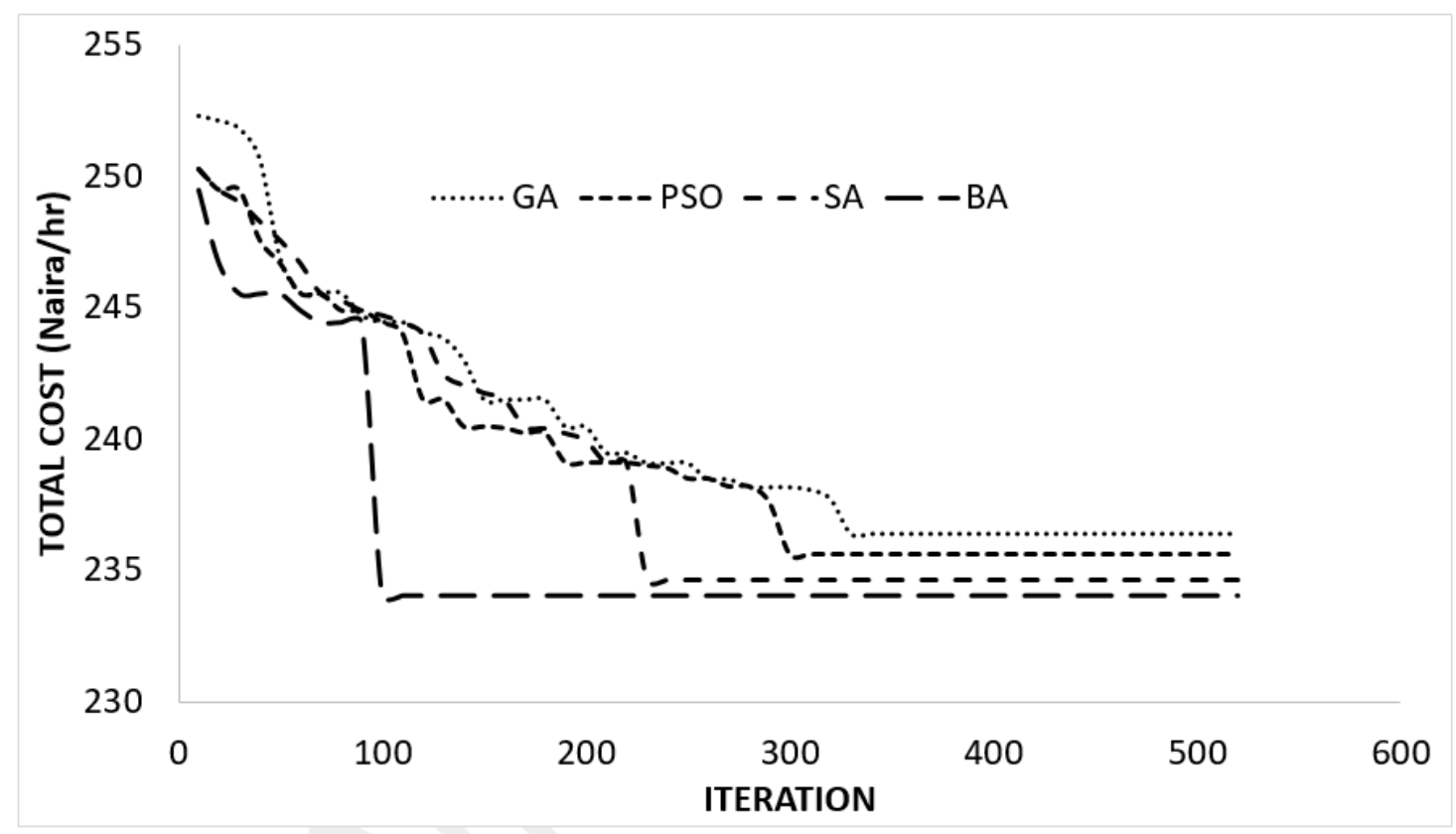

Figure 2: Graph showing the result of comparison between BA, GA, PSO and SA. 
[7] Olakunle, A. O. and Folly, K. A. "Economic Load Dispatch of Power System Using Genetic Algorithm with Valve Point Effect", Springer International Publishing, Vol. 1 No 9140, pp.276-284, 2015.

[8] Nuseirat, A. A., Tawalbeh, N. I. and Al-Musili, S. "Economic Power Dispatch Problem via Complementarity Problem Approach", International Journal of Electronics and Electrical Engineering, Vol. 5 No. 2 pp171-177, April 2017.

[9] Bakhta, N., Hamid, B. and Ahmed, A. "Solving the Economic Dispatch Problem by Using Tabu Search Algorithm", Elsevier Advancements in Renewable Energy and Clean Environment, 36 pp. 694-701, 2013.

[10] Rahmat, N. A., Musirin, I. and Abidin, A. F. "Differential Evolution Immunized Ant Colony Optimization (DEIANT) Technique in Solving Weighted Economic Load Dispatch Problem", Asian Bulletin of Engineering Science and Technology, Vol. 1 No. 1, pp17-26, 2013.

[11] Sharma, J. and Mahor, A. "Particle Swarm Optimization Approach for Economic Load Dispatch: A Review", International Journal of Engineering Research and Applications, Vol. 3 No. 1, pp.013-022, February 2013.

[12] Rahmat, N. A. and Musirin, I. "Hybrid Differential Evolution-Ant Colony Optimization for Economic Load Dispatch Problem", Journal of Theoretical and Applied Information Technology, Vol. 48 No. 2 pp.680-690 Feb. 2013.

[13] Nawaz, A., Saleem, N., Mustafa, E. and Khan, U. A. "An Efficient Global Technique for Solving the Network Constrained Static and Dynamic Economic Dispatch Problem", Turkish Journal of Electrical Engineering and Computer Sciences, 25, pp.73-82, 2017.

[14] Ahmed, I., Rao, A. R., Shah, A., Alamzeb, E. and Khan, J. A. "Performance of Various
Metaheuristic Techniques for Economic Dispatch Problem with Valve Point Loading Effects and Multiple Fuelling Options", Advances if Electrical Engineering, pp.1-14, Nov. 2014.

[15] Gautham, S. and Rajamohan, J. "Economic Load Dispatch using Novel Bat Algorithm," Presented at $1^{\text {st }}$ International Conference on Power Electronics, Intelligent Control and Energy Systems, 2016, pp. 1-4.

[16] Wulandhari, L. A., Komsiyah, S. and Wicaksono, W. "Bat Algorithm Implementation on Economic Dispatch Optimization," Presented at $3^{\text {rd }}$ International Conference on Computer Science and Computational Intelligence 2018, Issue 135, pp. 275-282.

[17] Preeti, I., Prakash, R. and Anguraja, R. "Economic Load Dispatch Optimization Using Bat Algorithm with Various Percentages of Load at Different Time Intervals," International Journal of Recent Trends in Engineering and Research, Vol. 3 No. 7. Pp.323-326, July 2017.

[18] Dao, T., Pan, T., Nguyem, T. and Chu, S. "Evolved Bat Algorithm for Solving the Economic Load Dispatch Problem," Springer International Publishing. Issue 329, pp. 109119, 2015.

[19] Thang, T. N. and Sang, D. H, "Bat Algorithm for Economic Emission Load Dispatch Problem," International Journal of Advanced Science and Technology, Vol. 86, pp. 51-60.

[20] Abanihi, V. K. "Economic Load Dispatch of Nigeria Integrated High Voltage Generation and Transmission Grid," PhD thesis, Department of Electrical/Electronic Engineering, University of Benin, Benin City, 2016.

[21] Transmission Company of Nigeria. Grid Operations, Annual Technical Report Issued by the Director National Control Centre Osogbo, 2015. 


\section{APPENDIX}

The loss co-efficient matrix of Nigerian 21 thermal power stations:

$B_{i j}=\left[\begin{array}{ccccccccccc}0.0037 & 0.0002 & -0.0074 & 0.0005 & 0.012 & -0.0076 & -0.0036 & 0.0037 & 0.0074 & 0.0005 & 0.0120 \\ 0.0002 & 0.0103 & 0.0033 & -0.0031 & 0.0022 & 0.0005 & -0.0011 & 0.0074 & 0.0076 & 0.0023 & 0.0130 \\ -0.0074 & 0.0033 & -0.0076 & 0.0023 & 0.013 & 0.0042 & 0.0152 & 0.0005 & 0.0023 & 0.0056 & 0.0149 \\ 0.0005 & -0.0031 & 0.0023 & 0.0056 & 0.0149 & 0.0004 & -0.0096 & 0.0120 & 0.0130 & 0.0149 & 0.0935 \\ 0.012 & 0.0022 & 0.013 & 0.0149 & 0.0935 & -0.0248 & -0.1354 & 0.0076 & 0.0042 & 0.0005 & 0.0248 \\ -0.0076 & 0.0006 & 0.0042 & 0.0004 & -0.0248 & 0.0127 & 0.0649 & 0.0036 & 0.0152 & 0.0096 & 0.1354 \\ -0.0036 & -0.0011 & 0.0152 & -0.0096 & -0.1354 & 0.0649 & 0.0769 & 0.0014 & 0.0017 & 0.0015 & 0.0019 \\ 0.0037 & 0.0074 & 0.0005 & 0.0120 & 0.0076 & 0.0036 & 0.0175 & 0.0017 & 0.0060 & 0.0013 & 0.0016 \\ 0.0074 & 0.0076 & 0.0023 & 0.0130 & 0.0042 & 0.0152 & 0.0184 & 0.0015 & 0.0013 & 0.0065 & 0.0017 \\ 0.0005 & 0.0023 & 0.0056 & 0.0149 & 0.0004 & 0.0096 & 0.0175 & 0.0019 & 0.0016 & 0.0017 & 0.0071 \\ 0.0120 & 0.0130 & 0.0149 & 0.0935 & 0.0248 & 0.1354 & 0.0154 & 0.0026 & 0.0015 & 0.0024 & 0.0030 \\ 0.0076 & 0.0042 & 0.0005 & 0.0248 & 0.0127 & 0.0649 & 0.0283 & 0.0022 & 0.0020 & 0.0019 & 0.0025 \\ 0.0036 & 0.0152 & 0.0096 & 0.1354 & 0.0649 & 0.0769 & 0.0037 & 0.0002 & -0.0074 & 0.0005 & 0.012 \\ 0.0014 & 0.0017 & 0.0015 & 0.0019 & 0.0026 & 0.0022 & 0.0002 & 0.0103 & 0.0033 & -0.0031 & 0.0022 \\ 0.0017 & 0.0060 & 0.0013 & 0.0016 & 0.0015 & 0.0020 & -0.0074 & 0.0033 & -0.0076 & 0.0023 & 0.0013 \\ 0.0015 & 0.0013 & 0.0065 & 0.0017 & 0.0024 & 0.0019 & 0.0005 & -0.0031 & 0.0023 & 0.0056 & 0.0149 \\ 0.0019 & 0.0016 & 0.0017 & 0.0071 & 0.00 .30 & 0.0025 & 0.012 & 0.0022 & 0.013 & 0.0149 & 0.0935 \\ 0.0026 & 0.0015 & 0.0024 & 0.0030 & 0.0069 & 0.0032 & -0.0076 & 0.0005 & 0.0042 & 0.0004 & -0.0248 \\ 0.0022 & 0.0020 & 0.0019 & 0.0025 & 0.0032 & 0.0085 & -0.0036 & -0.0011 & 0.0152 & -0.0096 & -0.1354 \\ 0.0218 & 0.0107 & -0.0036 & -0.0011 & 0.0055 & 0.0033 & -0.0075 & 0.0005 & 0.0015 & 0.0005 & 0.0075 \\ 0.0107 & 0.0107 & -0.0001 & -0.0079 & 0.0026 & 0.0028 & 0.0019 & 0.0001 & 0.0045 & 0.0001 & 0.0136\end{array}\right.$

$\left.\begin{array}{cccccccccc}0.0076 & 0.0036 & 0.0014 & 0.0017 & 0.0015 & 0.0019 & 0.0026 & 0.0022 & 0.0218 & 0.0107 \\ 0.0042 & 0.0152 & 0.0017 & 0.0060 & 0.0013 & 0.0016 & 0.0015 & 0.0020 & 0.0107 & 0.0107 \\ 0.0004 & 0.0096 & 0.0015 & 0.0013 & 0.0065 & 0.0017 & 0.0024 & 0.0019 & -0.0040 & -0.0020 \\ 0.0248 & 0.1354 & 0.0019 & 0.0016 & 0.0017 & 0.0071 & 0.0030 & 0.0025 & -0.0011 & 0.0018 \\ 0.0127 & 0.0649 & 0.0026 & 0.0015 & 0.0024 & 0.0030 & 0.0069 & 0.0032 & 0.0055 & 0.0026 \\ 0.0649 & 0.0769 & 0.0022 & 0.0020 & 0.0019 & 0.0025 & 0.0032 & 0.0085 & 0.0033 & 0.0028 \\ 0.0037 & 0.0002 & -0.0074 & 0.0005 & 0.012 & 0.0076 & -0.0036 & 0.0136 & 0.0175 & 0.0184 \\ 0.0002 & 0.0103 & 0.0033 & -0.0031 & 0.0022 & 0.0005 & -0.0011 & 0.0175 & 0.0154 & 0.0283 \\ -0.0074 & 0.0033 & -0.0076 & 0.0023 & 0.013 & 0.0042 & 0.0152 & 0.0184 & 0.0283 & 0.0161 \\ 0.0005 & -0.0031 & 0.0023 & 0.0056 & 0.0149 & 0.0004 & -0.0096 & 0.0075 & 0.0005 & 0.0015 \\ 0.012 & 0.0022 & 0.013 & 0.0149 & 0.0935 & -0.0248 & 0.1354 & 0.0019 & 0.0001 & 0.0045 \\ -0.0076 & 0.0005 & 0.0042 & 0.0004 & 0.0248 & 0.0127 & 0.0649 & 0.0005 & 0.0075 & 0.0001 \\ -0.0036 & -0.0011 & 0.0152 & -0.0096 & -0.1354 & 0.0649 & 0.0769 & 0.0075 & 0.0005 & 0.0015 \\ 0.0014 & 0.0017 & 0.0015 & 0.0019 & 0.0026 & 0.0022 & 0.0218 & 0.0107 & -0.036 & -0.0011 \\ 0.0017 & 0.0060 & 0.0013 & 0.0016 & 0.0015 & 0.0020 & 0.0107 & 0.0107 & -0.0001 & -0.0079 \\ 0.0015 & 0.0013 & 0.0065 & 0.0017 & 0.0024 & 0.0019 & -0.0004 & -0.0002 & 0.2459 & -0.0133 \\ 0.0019 & 0.0016 & 0.0017 & 0.0071 & 0.0030 & 0.0025 & -0.0011 & -0.0018 & -0.1328 & 0.0265 \\ 0.0026 & 0.0015 & 0.0024 & 0.0030 & 0.0069 & 0.0032 & 0.0055 & 0.0026 & 0.0118 & 0.0098 \\ 0.0022 & 0.0020 & 0.0019 & 0.0025 & 0.0032 & 0.0085 & 0.0033 & 0.0028 & -0.0792 & 0.0045 \\ 0.0055 & 0.0033 & 0.0026 & 0.0028 & -0.0118 & -0.0079 & 0.0098 & 0.0045 & 0.0216 & -0.0001 \\ -0.0012 & 0.0297 & 0.0218 & 0.0093 & 0.0028 & 0.0093 & 0.0228 & 0.0017 & 0.0028 & 0.0017\end{array}\right]$

